\title{
ADOÇÃO INTERNACIONAL: DISSONÂNCIAS ENTRE ESTATUTO DA CRIANÇA E DO ADOLESCENTE E CONVENÇÃO DE HAIA
}

\section{ARTIGO ORIGINAL}

COÊLHO, André Vitor ${ }^{1}$, FARIA, Rayanne Lara Santana de ${ }^{2}$, PINTO, Gilberto de Andrade ${ }^{3}$

COÊLHO, André Vitor. FARIA, Rayanne Lara Santana de. PINTO, Gilberto de Andrade. Adoção Internacional: Dissonâncias entre Estatuto da Criança e do Adolescente e Convenção de Haia. Revista Científica Multidisciplinar Núcleo do Conhecimento. Ano 06, Ed. 11, Vol. 05, pp. 106-123. Novembro de 2021. ISSN: 2448-0959, Link de acesso: https://www.nucleodoconhecimento.com.br/lei/adocaointernacional, DOI: 10.32749/nucleodoconhecimento.com.br/lei/adocao-internacional

\section{RESUMO}

O presente artigo tem como problemática a análise, sob o viés jurídico, das Adoções Internacionais ocorridas no Brasil, invocando como norte a coexistência do Estatuto da Criança e do Adolescente e a Convenção de Haia, visando explicar os motivos de ocorrerem dissonâncias em sua aplicabilidade, e a possibilidade que disto advenha, influxos pesarosos e morosidade no ato de adoção, tomando como foco o Princípio do Interesse da Criança. Concebe-se como objetivo fazer uma sinopse conceitual, histórica e evolutiva da Adoção no Direito de Família brasileiro, uma análise comparativa entre os sistemas de adoção aplicados no Brasil e em outros países, de modo a encontrar elementos que justifiquem o excesso de criteriosidade durante o processo legal, concomitante com a incompatibilidade de existirem crianças em situação de vulnerabilidade e Leis que permitam entraves burocráticos e morosidade processual. Cauciona-se, a partir de uma Pesquisa de Referencial Bibliográfico. Sendo notório que, toda criança e adolescente tem a prerrogativa de possuírem uma

\footnotetext{
${ }^{1}$ Acadêmico em Direito. ORCID: 0000-0002-2856-2529

${ }^{2}$ Acadêmica em Direito. ORCID: 0000-0001-6467-9814

${ }^{3}$ Orientador.
}

$\mathrm{RC}: 100872$

Link de acesso: https://www.nucleodoconhecimento.com.br/lei/adocao-internacional 
família e um lar, albergados na Constituição Federal e em outras leis pátrias, conclui-se que a existência de excesso de burocratizações, falta de instrução legal para possíveis adotantes, bem como, indicar a Adoção Internacional somente em última instância, interferem com o bem-estar, proteção, interesse e gozo dos Direitos Fundamentais da criança, devendo as leis e o sistema legal, promoverem maior efetividade nas adoções, com igual proteção, mas com a expansão do alcance de oferta, também para pretendentes estrangeiros.

Palavras-chave: Direito de Família, Adoção Internacional, Convenção de Haia e Estatuto da Criança e do Adolescente, Sistemas de Adoção, Princípio do Interesse da criança.

\section{INTRODUÇÃO}

'Mister' se faz assinalar que o presente artigo tem como problemática, trazer a baila uma análise situacional dos aspectos inerentes a problemática da Adoção Internacional e as dissonâncias entre Estatuto da Criança e do Adolescente e Convenção de Haia. Objetivando perceber os distanciamentos e congraçamentos entre ambas as Leis e o que torna a efetivação das adoções no Brasil, exponencialmente mais morosas. Usando para tal, a base metodológica da pesquisa de referencial bibliográfico.

Onde serão averiguadas a aplicabilidade legal, as dissociações ocorridas quanto das metas e objetivos acordados por ocasião da Convenção de Haia e a posterior ratificação brasileira, através do Decreto Lei n.ำ3.087/99 (BRASIL, 1999).

Com relação ao tema aludido no artigo, há que se definir qual a necessidade de haver leis e procedimentos que englobem o aspecto relativo à Adoção Internacional, portanto, a princípio será feito um apanhado historiográfico e conceitual do termo adoção e o percurso transcorrido por essa, especificamente no Direito de Família brasileiro. Em outro dizer, enfatizar-se-á as vertentes de adoção assumidas pelo Estatuto da Criança e do Adolescente, que teve como modelo inicial as diretivas decididas em Haia, mas que rumaram por caminhos disto da base ideológica, nos 
quais foram introduzidos pontos variantes e discordantes da real intenção de desburocratização. Em um terceiro estande abordará os procedimentos de Adoção Internacional, suas 'nuances' na resolução das adoções entre países consignatários ou não da Convenção de Haia. Ademais, há de se acrescentar um dado comparativo entre o processo de adoção ocorrido no Brasil e modelos utilizados em outros países e quais ilações negativa ou positiva advenham nos resultados logrados para o interesse das crianças e adolescentes em foco.

Num quinto momento abalroaremos a possibilidade de que as Leis brasileiras atinentes ao ECA (Estatuto da Criança e do Adolescente), estejam de alguma forma ulcerando o Princípio do Interesse da Criança. Por oportuno, no sexto Capítulo estaremos trabalhando a relevância do papel do Estado na construção e efetivação de Leis que alberguem garantias de Tutelação de Direitos às Crianças e Adolescentes, tal como a possibilidade deste estar omitindo-se na questão de suscetibilidade, as quais as crianças e jovens sofrem, quando precisam passar por processos de adoção.

A substância a ser aferida é o agravamento da situação de melindre que os jovens e crianças colocadas para adoção se encontram, quando Leis como as fixadas no ECA, impõe regras, que causem morosidade e desvirtuem do resultado fim esperado, o de bem-estar da criança e a garantia de direitos vitais para a dignidade humana, efetiva e a curto prazo. Desta feita realça-se que, a acepção do tema Adoção, é algo frágil e cheio de 'nuances', e de fato requer, de modo inquestionável, reflexões, não somente sobre a necessidade de amparo legal, mas de que modo este deve ser feito, e da eficiência e eficácia que os existentes possuem, sobre as relações e processos de perfilhamento.

RC: 100872

Link de acesso: https://www.nucleodoconhecimento.com.br/lei/adocao-internacional 


\section{DESENVOLVIMENTO}

\subsection{CONCEITO E HISTÓRIA DA ADOÇÃO NO DIREITO DE FAMÍLIA BRASILEIRO}

Etimologicamente, o termo Adoção origina-se do latim "adoptio, ônis" sendo o ato ou efeito de perfilhar, ou aceitar alguém, ou algo como filho, sem haver relação natural com este. Na esfera jurídica, adoção é o processo legal que consiste no feito de consciente e espontaneamente anuir como membro integrante da família, com todos os direitos legais, indivíduo que não pertença ao núcleo familiar comum e natural.

Segundo Diniz (2007), o termo adoção assim se conceitualiza:

Um ato jurídico solene e bilateral que gera laços de paternidade e filiação entre pessoas naturalmente estranhas umas às outras. Estabelece um vínculo fictício de filiação, trazendo para sua família, na condição de filho, pessoa que geralmente Ihe é estranha. É uma ficção legal que possibilita que se constitua entre o adotante e o adotado um laço de parentesco de $1^{\circ}$ grau na linha reta, estendendo-se para toda a família do adotante. É um ato complexo que depende de intervenção judicial, de caráter irrevogável e personalíssimo. (DINIZ, 2007, p. 483 - 484).

Já Beviláqua (1906) define como sendo: "O ato civil pelo qual alguém aceita um estranho na qualidade de filho". (BEVILÁQUA, 1906).

Em termos, a adoção não tem limitação cronológica atual, mas remonta época da Antiguidade, dado que, era usada como recurso para assentar família com prole, quando essas não surgissem de forma natural, por meio da união matrimonial, citando Jean Carbonnier:

A adoção como forma constitutiva de vínculo de filiação, teve evolução histórica bastante peculiar. $O$ instituto era utilizado na antiguidade para perpetuar o culto doméstico. Atualmente, a filiação adotiva é uma filiação puramente jurídica, baseando-se na presunção de uma realidade não afetiva. (VENOSA, 2018, p. 317).

No Brasil a ideia de adoção foi introduzida por meio das Ordenações Filipinas e de uma Lei de 1828, com características do Direito português e que, determinava que deveria ser instaurado um processo judicial para a realização de audiência e entrega

RC: 100872

Link de acesso: https://www.nucleodoconhecimento.com.br/lei/adocao-internacional 
de uma Carta de Recebimento do filho. Evolutivamente, a dimensão assumida pela adoção se relacionava ao estabelecido no Código Canônico, que possibilitava ao homem o direito de adotar para que assim, pudesse ter herdeiros e perpetuar a linhagem, e a bem, praticar a caridade.

Em tal cenário, as crianças órfãs ou abandonadas eram colocadas nas então chamadas "Rodas dos Expostos ou Roda dos Enjeitados", que ficavam em frente as Santas Casas de Misericórdias, administradas pela Igreja Católica. Ao serem recebidas eram entregues a amas de criação, que cuidariam destas e as remeteriam ao acolhimento de famílias desejosas em agir com caridade. Contudo, em sua grande maioria, essas crianças não encontravam famílias que thes acolhessem e culminavam em ficarem expostas à própria sorte ou perecerem. A aceitação de indivíduos rejeitados, como eram chamados, era o último recurso para evitar o total deperecimento de famílias e seus respectivos nomes.

Em se tratando de legalidade do ato, vemos que a adoção tinha simples e esparsas referências em nossas leis pátrias, necessitando recorrer a consultar ao Direito Romano para sanar dúvidas e lacunas interpretativas existentes. O processo de adoção recebia a legitimação da autoridade pública e a confirmação de um juiz de primeira instância, que como a Lei, 22 de setembro de 1828 (BRASIL, 1828) determinava, em seu artigo 1.., § 1...: tinha a competência de conceder Cartas de Legitimação tanto para os filhos ilegítimos, quanto para adotados.

A legislação e o direito no Brasil caminharam a passos lentos, desde sua introdução no país e após o Cisma ocasionado pela laicização do Estado brasileiro. Somente com o advento do primeiro Código Civil Brasileiro (BRASIL, 2004), baseado sobre os moldes do Código Napoleônico, datado de 1916 e que vigorou até 2002, com o advento da Lei 10.406 (BRASIL, 2002), que trouxe consigo entre tantos enfoques, a necessidade de estabelecer critérios e regras para o casamento civil (instituído no ano de 1890), o que convenientemente, precisou de aporte legal, instaurando um livro dedicado ao Direito de Família, onde dentre outros temas, vemos a temática sobre adoção aludida de modo elucidativo em seu capítulo V, dos artigos 368 ao 378 (BRASIL, 2004). Determinando que somente os maiores de 50 (cinquenta) anos, 
sem prole legítima ou ilegítima poderiam adotar; o adotante deveria ter uma diferença de idade de no mínimo 18 (dezoito) anos em relação ao adotado; em regra, a adoção só poderia ser efetivada por um único adotante, salvo exceção se estes fossem cônjuges; o processo não poderia ocorrer sem o conhecimento e consentimento da pessoa que fosse a representante legal do adotando; ao adotado era permitido romper o laço de adoção no exato instante de sua maioridade. Essa nulidade do ato de adoção também se estendia a ocorrência de ingratidão por parte do adotado para com o adotante ou quando ambos acordassem positivamente para a quebra do vínculo estabelecido.

Com efeito, no ano de 1957, com a Lei n. $3.133 / 57$ (BRASIL, 1957), temos uma mudança significativa no olhar legal lançado para as adoções, onde 0 ato de adotar deixa de ser por puro fator de suprir a necessidade de se ter uma prole, para os homens darem continuidade a seu nome familiar, e assim manterem os bens amealhados dentro daquela família. E assumindo a configuração de assistência ao adotado, quando permite que casais a partir dos 30 (trinta) anos, com ou sem filhos pudessem adotar.

Ressalta-se que, em 1965, criou-se a Lei de n. 4.655 (BRASIL, 1965), que concedia Legitimidade do infante exposto, garantindo quase todos os direitos ao adotado, exceto em casos de sucessão com filhos legítimos. Todavia, em 1979, promulga-se a Lei n. 6.697/79 (BRASIL, 1979), que legisla sobre o Código do Menor, onde soçobra a legitimação da adoção e começa a constar três modelos de adoção. Sendo a que tem respaldo e deferimento no Código Civil e destinava-se a pessoas de qualquer idade; a Adoção Simples destinada a menores em situação irregular e de abandono; e a Adoção Plena que concedia laços sanguíneos e a condição de filho legítimo ao adotando, extirpando em definitivo as ligações com a família de origem e reconhecendo o Direito Sucessório ao adotado.

Seguramente, com a promulgação da Constituição brasileira em 1988, o avanço sobre o assunto assume o prisma de proteção, amparo e dignificação para a criança e adolescente adotados. Moldando novos rumos para o Direito de Família no Brasil, pois não somente se percebe e trata a adoção como algo necessário a proteção, 
dignidade humana e direito universal do indivíduo a um lar e família. Como também, passa a equiparar os filhos sejam eles consanguíneos ou não. Nesta vereda, passou-se a ter os filhos adotados, direito na sucessão hereditária, em razão da Carta Magna (BRASIL, 1988), em seu capítulo VII, artigo 227, § 6. vetar qualquer discriminação filial. Acrescenta-se ainda que na mesma, no mesmo Capítulo VII, artigo 227, no $\S 5$. , dá entrada para o enfoque da Adoção Internacional, ao determinar que:

Art. $227-\S 5 .^{\circ}:$ A adoção será assistida pelo poder público, na forma da lei, que estabelecerá casos e condições de sua efetivação por parte de estrangeiros. (BRASIL, 1988).

No ano seguinte a promulgação da Constituição de 1988, foi instituída a Convenção da Organização das Nações Unidas, sobre os Direitos da Criança e do Adolescente, assinado em assembleia-geral por todos os Estados participantes da convenção, entre estes o Brasil. Em que, os países membros se comprometiam com o zelo, bem-estar, segurança, proteção, integração social e familiar da criança e adolescente. O Brasil, ratificou tal intenção através do Decreto n.․ 99.710/90 (BRASIL, 1990), as ideias ali discutidas e acordadas, deram aporte determinante para a edição da Lei 9.069/90 (BRASIL, 1990), conhecida como Estatuto da Criança e do Adolescente - ECA.

\subsection{PROCESSO DA ADOÇÃO INTERNACIONAL SEGUNDO O ESTATUTO DA CRIANÇA E DO ADOLESCENTE}

Delineia-se oportuno lembrar que, embora hajam indivíduos que desejem e busquem estabelecer família, incluindo prole. Temos uma sociedade constituída de singularidades entre seus membros. Cada quais com seus próprios encargos e psique. Nem todos estão preparados para assumirem as responsabilidades de conceberem e criarem suas filiações. Restando como consequência, considerável número de crianças e jovem em situação de abandono e risco social, não somente em nosso país como à nível mundial.

RC: 100872

Link de acesso: https://www.nucleodoconhecimento.com.br/lei/adocao-internacional 
De sorte, tal situação passou a ser vista com olhar de esmero e zelo por parte de Organizações e Governos ao entorno do globo. E meios de coibir, sanar e proteger crianças, adolescentes e jovem, dessa categoria de infortúnio e exposição tem sido pensados. Acordos tem sidos firmados e Leis tem sido criadas. Tais quais a Declaração Universal do Direito das Crianças (ONU, 1959), que possibilitou a criança ser vista como sujeito de direito, incluindo incumbir tanto a sociedade como as autoridades públicas da obrigatoriedade de propiciarem as crianças sem família ou carentes, cuidados especiais e meios adequados para subsistência. Assomandose a Constituição Federal brasileira, de 1988, que determina em seu Capítulo VII, artigo 227 (BRASIL, 1988), ser dever da família, da sociedade e do Estado, assegurar tanto a criança, como ao adolescente e ao jovem, o direito absoluto e prioritário à convivência familiar, entre outros direitos basilares. Ademais, deixá-los a salvo de toda forma de negligência, discriminação, exploração, violência, crueldade e opressão.

Neste diapasão tivemos a Convenção da ONU (ONU, 1989), sobre os Direitos da Criança, que ratifica a ideia de que elas possuem direitos especiais a cuidados $\mathrm{e}$ proteção, devendo crescer em um ambiente familiar para alcançar um desenvolvimento pleno e harmônico. Além da Convenção de Haia (HAIA, 1993), que traçou critérios de proteção das crianças de serem expostas a riscos de adoção ilegal, prematura e contrabando humano, e segundo Wilson Donizeti Liberati (2009, p. 41), serviu como instrumento eficaz para a austeridade e refreamento da clandestinidade e antijuridicidade, existentes nas adoções internacionais, além de modelo para nortear as adoções entre países, com respaldo legal e aceite internacional. Todos esses eventos, forjaram o referencial de constituição, criação e advento do ECA. (Estatuto da Criança e do Adolescente), que contém postulado doutrinário sobre proteção ampla e integral da criança e do adolescente.

A Legislação brasileira indica que os aspectos inerentes a adoção de maiores de 18 (dezoito) anos é regida pelo Código Civil, e todas as relacionadas aos menores de 18 (dezoito) anos, devem ser disciplinados pelo Estatuto da Criança e do Adolescente, primando pelo mais adequado e vantajoso para a criança. De feito, 
com o primordial intuito de delimitar prioridade ao bem-estar e proteção das crianças, em situação de adoção em nosso país, o ECA, trouxe impetrado em suas letras, regras firmes e impositivas, para permissão de adoções com abrangência internacional, enumeradas no Capítulo III, subseção IV, artigos 51 ao 52D (BRASIL, 1990).

E assim, amoldando-se a realidade, ressalta-se que, os Procedimentos de Adoção Internacional, de crianças brasileiras por casais estrangeiros, seguem determinadas especificidades legais impostas pelo ECA: primeiramente o estrangeiro deve habilitar-se na Autoridade Central (quaisquer informações sobre as autoridades podem ser obtidas através do endereço eletrônico da Convenção de Haia de Direito Internacional Privado) de seu país; tais autoridades deverão elaborar um arquivo sobre os adotantes; deverá escolher-se o Estado brasileiro, para encaminhamento do Processo de Adoção, por intermédio de Organismos Estrangeiros credenciados no Brasil, entes Governamentais, Autoridade Central Administrativa Federal ou pela CEJAls, que existem nos TJ de todos os Estados.

Observa-se que, nos casos em que o dossiê for remetido diretamente da Autoridade Central Estrangeira, para Autoridade Central Administrativa Federal, será importantíssimo informar à qual Estado brasileiro, os requerentes desejam habilitarse para Adoção Internacional, com a finalidade de que, os autos sejam endereçados diretamente para aquela Unidade Federativa. Visto que, a habilitação da adoção, ocorre toda no TJ do Estado escolhido, com as Comissões Estaduais Judiciárias de Adoção Internacional.

Serão solicitados: documentos; requerimento de habilitação na referente comissão, assinados pelos requerentes ou por seus representantes, com assinaturas reconhecidas; uma declaração de gratuidade e de sigilo de adoção no Brasil, devidamente assinada e com firma reconhecida, cujo formulário é fornecido pela própria Comissão; procuração do representante, caso seja constituído um; atestado de sanidade física e mental; certidões negativas de antecedentes criminais; certidão de residência expedida por órgão oficial; certidão de renda (declaração de profissão e rendimentos); certidão de casamento ou prova de união estável, caso os RC: 100872

Link de acesso: https://www.nucleodoconhecimento.com.br/lei/adocao-internacional 
pretendentes sejam casados ou companheiros; certidão de nascimento; passaportes; autorização ou consentimento de órgão competente do país de origem para a adoção de uma ou mais crianças estrangeiras; fotos dos pretendentes; fotos da residência em que habitam; estudo psicossocial realizado no país de origem; a legislação do país de origem; a legislação do país atinente ao tema, previsto no art. 52, inciso IV do ECA (BRASIL, 1990); comprovação da existência de filhos ou não; e por seu turno, a ciência de que não podem ter contato no Brasil, com os pais biológicos da criança ou do adolescente, nem com qualquer pessoa que detenha a guarda anterior.

A adoção Internacional é condicionada a fatores de exceção, pois a criança e jovem só poderão ser encaminhados para habilitação da adoção por indivíduos estrangeiros, nas circunstâncias em que, o Juízo da Infância e da Juventude tenha examinado adequadamente o caso e chego à conclusão de impossibilidade de colocação do adotado em alguma família substituta nacional na sua jurisdição, definido estar a criança ou adolescente disponível para adoção por intermédio do cadastro da CEJAI, expedindo laudo de habilitação pela Comissão Estadual Judiciária de Adoção Internacional. Outrossim, o processo de adoção terá um período mínimo de acompanhamento e estágio assistido, do adotante com adotando, em território nacional, assim a destacar, de 15 (quinze) dias para crianças até dois anos e, de 30 (trinta) dias no mínimo para os maiores de 2 (dois) anos. Como o envio de crianças e jovens para o exterior só é permitido com autorização judicial, a saída do adotando só será autorizada, após correrem todos os trâmites, cumprido o múnus legal e, considerado o adotante ter as qualidades necessárias para garantir o bem-estar do adotando. Como Liberati (2009, p. 114) comenta, em seu Manual de Adoção Internacional, a ação de adoção chegará ao fim, somente após sentença constitutiva, criando assim, um novo vínculo de filiação entre adotando e adotado. Ademais, este afirma que:

$O$ adotante estrangeiro, ao ser informado de que a sentença transitou em julgado, torna-se, pela vontade da lei, o detentor do poder familiar em relação ao adotado, com todas as obrigações dele decorrente. Tal é o efeito que a sentença provoca na mudança de filiação, que a lei não distinguirá se o vínculo se originou pela via biológica ou se foi constituído pela adoção: a

RC: 100872

Link de acesso: https://www.nucleodoconhecimento.com.br/lei/adocao-internacional 
filiação, agora, é uma só, sem rótulos ou classificações. (LIBERATI, 2009, p. $117-118)$.

Portanto, a adoção seja nacional ou internacional, gera ao adotado vínculo e posição de filho, com todos os direitos e deveres, até mesmo de sucessão, sem quaisquer discriminações, desligando este das ligações familiares com seus pais biológicos, familiares e parentes. Bem como, no caso das internacionais, desconstituindo a nacionalidade de origem e adquirindo uma nova, correspondente ao do país de acolhida.

\subsection{PROCEDIMENTO DE ADOÇÃO INTERNACIONAL}

Nessa assentada, temos então que, na Adoção Internacional, em termos gerais, possui procedimentos específicos para aqueles que tenham o anseio de adotar crianças provenientes de países que não sejam os mesmos de residência do candidato a adotante. Inicialmente, para a segurança e proteção do adotado, nos processos de Adoção Internacional, deve ser observado se, o país de origem do adotando participou e ratificou o acordado na Convenção de Haia.

À primeira vista, a Convenção de Haia somente é executada entre os países que a aderem, em se tratando de outros países, não pertencentes a esse acordo, o que prevalece são as regras de adoção nacional, sem a intervenção das Autoridades Centrais, conforme prevê o Estatuto da Criança e do Adolescente:

Art. 52-D - Nas adoções internacionais, quando o Brasil for o país de acolhimento e a adoção não tenha sido deferida no país de origem porque a sua legislação a delega para o país de acolhida, ou ainda, na hipótese de, mesmo com a decisão, a criança ou adolescente ser oriundo de país que não tenha aderido à Convenção referida, o processo seguirá as regras da adoção nacional. (BRASIL, 1990).

Portanto, segundo o dispositivo legal supracitado, mesmo que não haja a interveniência de uma Autoridade Central, protegida pelo acordo firmado em Haia, ainda existe a possibilidade da adoção entre países, observando determinados procedimentos processuais.

RC: 100872

Link de acesso: https://www.nucleodoconhecimento.com.br/lei/adocao-internacional 
Nas circunstâncias em que, são brasileiros entrando com processo de adoção internacional, solicita-se que o país de acolhida da criança permita que, o procedimento ocorra no Estado Brasileiro, em caso positivo, os pretendentes devem requerer a habilitação para adoção, seguindo os parâmetros da adoção brasileira, na comarca da sua residência. Prontamente a habilitação, os documentos devem ser traduzidos e enviados para o país de origem da criança. Findo o processo de adoção no exterior, é emitida uma nova certidão de nascimento da criança, que deverá ser registrada no Consulado brasileiro, por intermédio da homologação da sentença estrangeira pelo Superior Tribunal de Justiça, em conformidade com o regramento do Ministério das Relações Exteriores (MRE).

No campo material, a adoção no exterior, quando a legislação do país originário da criança permitir, pode ocorrer sem prévia habilitação e, feita diretamente no país de acolhida da criança. Insta salientar que, deverá atentar-se para a existência de permissão no país do adotando, de que os visitantes ou residentes temporários podem adotar. Estando concluída esta etapa, será feito um procedimento idêntico ao do explicitado no 'item' anterior, emitindo-se assim, uma nova Certidão de Nascimento da criança, homologada mediante sentença estrangeira pelo STJ, conforme as regras do Ministério das Relações Estrangeiras (MRE).

Há de se acrescentar que, em referindo-se a casos em que brasileiros estejam adotando crianças de países estrangeiros, desde que o país onde o procedimento de adoção esteja sendo feito, permita a conclusão processual em território brasileiro, e todos os trâmites de adoção no Brasil tenha terminado, os pretendentes adotantes podem regressar ao país com a criança, aguardando em território nacional a conclusão e deferimento do processo. Contudo, os adotantes devem atentar para as regras de vistos de entrada e saída de pessoas, aplicadas no país de origem, de modo que a criança possa residir em seu país de acolhida, sem quaisquer impedimentos. O pedido de visto, desde que cabível, é feito no Consulado Brasileiro, seguindo as regras do MRE. Ressalta-se que, os pretendentes devem solicitar e dar prosseguimento a adoção internacional, na Vara da Comarca ondem residem. 
Destarte, quando a adoção é feita entre países ratificantes da Convenção de Haia, por residentes brasileiros, as regras a serem seguidas são: habilitar-se na vara da comarca de sua residência, segundo as regras do seu Tribunal de Justiça; após o recebimento da habilitação, os pretendentes devem requerer ao Juízo da sua respectiva comarca, que uma cópia do processo seja encaminhada à Comissão Estadual Judiciária de Adoção Internacional (CEJAI), indicando o país em que pretende adotar a criança. Inobstante isso, o Brasil não possui organismo que atue em matéria de adoção internacional. A Autoridade Central Administrativa Federal, envia um pedido para a Autoridade Central do país da criança, para requerer as informações e orientações adicionais, quanto aos procedimentos que deverão ser seguidos e a legislação interna daquele país. A documentação em Língua portuguesa, deve ser traduzida por um tradutor público juramentado, para o idioma do país de origem da criança a ser adotada.

\subsection{O SISTEMA DE ADOÇÃO INTERNACIONAL BRASILEIRO E O DE OUTROS PAÍSES EM DESENVOLVIMENTO}

Gnosiologicamente falando, os fatos são a mola propulsora que antecedem o Direito e exige que este venha normalizar a situação. Assim, cada sociedade com suas singularidades e peculiaridades, possuem regras próprias, que por vezes, diferem das de outros países. Esta é a situação que se acerca nas Adoções Internacionais, mesmo que as Leis versem sobre o mesmo tema, a realidade existente em cada Estado Nação, forja a necessidade de criarem-se dispositivos legais, que por vezes, possuem pontos divergentes, causadores de embates, morosidade e possível inviabilidade nas adoções.

Um indicativo objetivo destes dispositivos que diferem das adoções internacionais aplicados em outros países seria o ECA em seu artigo 51, § 4. (BRASIL, 1990), determinar ser vetada a saída do adotando do território nacional, antes de ter sido transitada e consumada a adoção, que embora revogado pela Lei $n .$. 12.010/2009 (BRASIL, 2009), acabou por apenas ser lapidada a grafia, mas possuindo teor similar, passando a ser mencionada e incluída, no artigo 52, § 8.. da Lei 8.069/90 
(BRASIL, 1990), onde estabelece que enquanto não houver sido transitada em julgado a decisão de consentimento da adoção internacional, o adotando não poderá sair do território brasileiro.

Aliás, por ocasião da Convenção de Haia, foi aberto um parêntese para a possibilidade de a Adoção Internacional ser levada a termo no país de acolhida, porém no caso específico do Brasil, isso é impossível, dado que, no artigo 147, inc. I e II da Lei 8.069/90 (BRASIL, 1990), dispor que a competência acerca da adoção deverá ser determinada pelo domicílio dos pais ou responsáveis, ou na falta deles, pelo lugar onde se encontra a criança ou adolescente.

Cumpre examinarmos que, o Sistema de Adoção Internacional aplicado no Brasil é ímpar em comparação ao aplicado em países desenvolvidos. No caso específico do nosso país, passamos por episódios onde as crianças e jovens em décadas anteriores, viviam em situação de risco social, exploração de mão-de-obra e sexual, com inúmeros episódios de descaso e negligência por parte do pátrio poder familiar, do Estado e sociedade. Por ocasião da construção do ECA, houve um profundo embate de ideias, entre diversas representações sociais, até chegar em um consenso. Durante essa construção, buscou-se resguardar a criança e ao adolescente, de todas as possíveis adversidades sociais, que viessem atentar e ferir o bem-estar e os direitos basilares, que estes, enquanto cidadãos possuem. Assim, muitos pontos que a princípio eram necessários e para defesa da criança, se tornaram dissonantes, burocráticos e entraves processuais.

Comparativamente, o Sistema de Adoção Internacional em países desenvolvidos em sua maioria possui regras claras e definidas, mas busca por celeridade processual, bastando que não haja alguma espécie de contestação sobre a adoção, qualquer pessoa maior de idade pode solicitar o deferimento do pedido de adoção, desde que cumpra todos os requisitos básicos solicitados, apresentando provas de possuir os requisitos necessários para adoção, além de mostrar evidências de que a adoção prima pelo melhor interesse da criança. Tendo passado por toda essa fase protocolar e de anamnese. Será dado provimento e feita uma investigação sobre o candidato a adotante, construído um relatório que será enviado ao tribunal, com a 
indicação de avaliação positiva ou negativa para adoção. Somente nesse momento serão chamados os pais biológicos, se encontrados, para manifestarem opinião sobre a adoção e declinarem do poder familiar existente. Após esse processo será deferida ou indeferida a adoção.

A título de esclarecimento, o procedimento da Adoção Internacional segue regramentos específicos quando o processo é feito entre os países ratificantes da Convenção de Haia, tornando o processo moroso pela burocracia instituída pelas CEJAls, e pela Autoridade Central Administrativa, em vista ser regida pelo ECA, e pelas leis que tratam a respeito da adoção nos países dos pretendentes. Cumpre salientar que, na adoção entre os países que um deles não é ratificante da supramencionada Convenção de Haia, o procedimento é mais célere, aplicando-se as regras da adoção brasileiras.

\subsection{VIOLAÇÃO DO PRINCÍPIO DO INTERESSE DA CRIANÇA SOB O ASPECTO DO ECA}

Outro ponto que parece decisivo na questão da Adoção Internacional, é o aspecto do bem-estar e interesse superior da criança, como questão sine qua non, para ocorrer todo o processo de relocação da criança e jovem, já que estas, ainda não possuem condições físicas, mentais, legais e financeiras de buscarem pelos próprios meios os direitos que lhes são garantidos constitucionalmente.

No aspecto legal do ECA, segundo Castro (2019, p. 89), vemos a existência da concepção de proteção à criança, utilizando para isto, do Princípio do Melhor Interesse da Criança. Assoma-se a este o Princípio da Prioridade em relação à família brasileira, onde busca-se criar medidas de proteção e segurança contra a desvirtuação do sentido primeiro da adoção, seguido da garantia de promover as crianças e jovens a possibilidade de manterem os traços culturais, linguísticos e de nacionalidade, necessários para a sensação de pertencimento tanto a um lar como a uma pátria.

RC: 100872

Link de acesso: https://www.nucleodoconhecimento.com.br/lei/adocao-internacional 
Contudo, visto que, os postulados estabelecidos pelo ECA, ditam que as crianças e adolescentes possuem direitos fundamentais e protetivos integrais, com prioridade absoluta e inalienáveis. Todas as ações legais estabelecidas no mesmo, deveriam pautar por expor a criança e jovem postos para adoção, ao mínimo embaraço, transtorno e exposição as mazelas que estarem em Centros de Acolhimento ou em Instituições públicas, podem causar ao psicológico da criança. Mas quando as regras de adoção estabelecida no Estatuto da Criança e Adolescentes, priorizam a tutela para parentes e adoção primeiramente apenas para brasileiros, relegando as internacionais para último plano, predito em seu artigo 31, na forma da lei:

Art. 31 - A colocação em família substituta estrangeira, constitui medida excepcional, somente admissível na modalidade de Adoção. (BRASIL, 1990).

Fato este, reafirmado pela Lei de Adoção, quando enfatiza a concepção de predileção a família consanguínea, para guarda e adoção de crianças. Como Castro afirma, em sua obra, Adoção Internacional (2019, p. 46), a Lei n.o 12.010/2009 (BRASIL, 2009), teve como meio fim, legislar sobre os temas inerentes ao ECA, visando agilizar o processo de adoção, contudo, acabou por reforçar a necessidade de que crianças e jovens em situação de desamparo familiar, sejam colocadas a priori e enfaticamente em suas famílias naturais, episódio repetido por efusivas 11 (onze) vezes, durante o texto da lei, o que prolonga o processo de adoção em busca de alguém que aceite esses jovens indivíduos, gerando burocratização em todo o trâmite de adoção.

Alargando a possibilidade de que essas crianças passem anos nessas Casas de Acolhimento, e até mesmo cheguem a maioridade sem encontrarem uma família brasileira que as deseje adotar. Tanto quanto, é uma agressão e trauma para elas, serem deixadas em regime de guarda provisória com parentes, que no futuro thes devolverá para a tutela do Estado, causando o vácuo existencial e sensação irrefutável de um segundo abandono.

Oportuno se torna dizer, que especificamente os brasileiros possuem um perfil clássico para adoção, baseado na procura por crianças em tenra idade, brancas ou de pele clara e sem doenças pré-existentes. O que de longe não é a realidade do 
país, quanto aos estrangeiros, que buscam a adoção internacional, a mentalidade por um perfil clássico é irrelevante, em geral, este é o último fio de esperança para se tornarem pais, o que os leva a não se basearem em diferenças, o filho que thes vier serão, aceitos de bom grado.

Aqui importante se faz dizer que, não só o aspecto de meticulosidade para proteger a criança de indivíduos perniciosos deve ser considerado, mas também os dispositivos usados para a adoção, deveriam primar pela otimização de tempo de permanência destes a espera de adoção. Principalmente, levando-se em consideração que, o laudo de habilitação expedido tem validade máxima de 1 (um) ano, e os processos de adoção quando abertos, por vezes chegam a durar cinco anos, entre idas e vindas processuais, devido ao excesso de burocracia. As normas estabelecidas no ECA e que por excesso de pormenorização e proibições, avilta inequivocamente o Princípio do Interesse da criança.

\subsection{OMISSÃO DO ESTADO BRASILEIRO A RESPEITO DAS CONDIÇÕES DE VULNERABILIDADE DAS CRIANÇAS}

No ordenamento jurídico brasileiro, no que tange as crianças e adolescentes, é dever da família, do Estado e da sociedade a promoção absoluta aos direitos fundamentais que são inerentes a vida humana, previsto no caput do artigo 227 da CF.:

Art. 227 - É dever da família, da sociedade e do Estado assegurar à criança, ao adolescente e ao jovem, com absoluta prioridade, o direito à vida, à saúde, à alimentação, à educação, ao lazer, à profissionalização, à cultura, à dignidade, ao respeito, à liberdade e a convivência familiar e comunitária, além de colocá-los a salvo de toda forma de negligência, discriminação, exploração, violência, crueldade e opressão. (BRASIL, 1988).

Aliás, os direitos concernentes às crianças e adolescentes previstos na própria Constituição Federal, são garantias fundamentais. No entanto, o Estado é omisso a partir do pressuposto, que há crianças em condições de vulnerabilidade. A intervenção do Poder Público é de suma importância nestes casos, para resguardar 
os direitos que estão sendo violados, pela entidade familiar, que não oferece condições favoráveis, para que a criança e jovem tenha um desenvolvimento salutar.

Nos moldes dos dispositivos legais, uma das maneiras de resguardar os interesses das crianças é a família substituta, ou seja, a adoção mesmo que sendo exceção, pode ocasionar melhores condições de vida para a criança. Contudo, embora haja a possibilidade de adoção para pessoas de outros Estados Nações, esta é considerada o último recurso a ser explorado e utilizado, até mesmo, nos casos de Adoção Internacional, se opta por preferencialmente escolher os brasileiros, residentes em países estrangeiros, em detrimento a casais estrangeiros.

Tanto as Adoções Nacionais como as Internacionais, possuem o objetivo de acolhimento das crianças que não tiveram os seus Direitos assegurados por suas famílias biológicas, ferindo a Carta Magna que prevê ser este dever da família. No entanto, quando um casal estrangeiro, pretende adotar uma criança brasileira, o processo é moroso e burocrático. Remetendo a indagação da doutrinadora Maria Helena Diniz:

Será possível rotular o amor de um pai ou de uma mãe como nacional ou estrangeiro? Não há razão para não se acolher a pretensão de estrangeiros interessados na adoção, que podem proporcionar afeição, carinho e amparo às crianças e adolescentes necessitados. (DINIZ, 2021, p. 619).

Neste sentido, o Estado é falho ao não zelar pelas crianças e adolescentes em situação de vulnerabilidade, desrespeitando o disposto da Lei Maior. Pois, a adoção visa resguardar os direitos do indivíduo em situação de fragilidade, e a colocação da criança em família substituta estrangeira, não deveria estar em situação de desigualdade, em comparação daquelas adotadas por casais brasileiros. Até mesmo, pois ao serem adotadas por estrangeiros, poderão ter melhores condições de vida, sob o aspecto educacional, trazendo oportunidades que não seriam ofertadas para crianças brasileiras, adotadas por famílias residentes no país. 


\section{CONSIDERAÇÕES FINAIS}

Ao longo desse, buscou-se identificar os pontos dissonantes entre o Estatuto da Criança e do Adolescente e a Convenção de Haia, nos aspectos das Adoções Internacionais no Brasil, de modo a esclarecer o que causa o excesso de tempo e de permanência de crianças e adolescentes em casas de apoio e centros de adoção, e em que ponto pode-se mudar para dar maior celeridade processual.

Notou-se que a construção de todo o processo laboral das leis que giram em torno da adoção na Legislação brasileira e repercutem na efetividade da mesma, foi moroso, conflituoso, cercado de antagonismos, envolvendo uma avalanche de eventos que corroboraram para a criação de um processo meticuloso e com regras firmes, de modo a coibir o tráfico humano de crianças, a exploração sexual e de trabalho infantil ou o despatriamento, assumindo característica de dispositivo que possibilite a segurança do ato de adoção, mas que causa entrave processual e radicalismos, que entram em conflito com o interesse da criança.

Em síntese é insofismável a existência de regulamentações para salvaguardar os interesse e direitos das crianças e jovens. E o ECA, possui bases diretivas louváveis e necessárias. Os processos de Adoção Internacionais necessitam passar por uma triagem criteriosa, pois o bem a ser tutelado e protegido pelo Estado, não detém autonomia e capacidade próprias, para garantir a seguridade de seus interesses.

A crítica a ser tecida, não é contra o Estatuto da Criança e do Adolescente, na questão de rigorosidade, mas ao fato de que, a Adoção Internacional deveria ser colocada no mesmo patamar das nacionais, em razão de possibilitar ao adotando um alargamento de perspectiva de encontrar um lar que o acolha, aceitando-o com todas as características que o permeie, Ihe garantido direitos basilares irrevogáveis e inalienáveis.

Minimizando assim, o tempo de permanência em Casas de Acolhimento, o refreamento das condições de vulnerabilidade do indivíduo em questão, o respaldo 
absoluto e efetivo do Princípio do Interesse da Criança e do Princípio da Prioridade Absoluta, bem como, desonerando os cofres do Estado.

\section{REFERÊNCIAS}

BEVILÁQUA, Clóvis. Em Defezado Projecto de Código Civil Brazileiro. Rio de Janeiro: Livraria Francisco Alves, 1906. Disponível em: http://www2.senado.leg.br/bdsf/handle/id/224223 Acesso: 18/08/2021

BRASIL. Constituição Federal (1988). 7.ㄹ ed. — Barueri: Manole, 2015.

BRASIL. Lei n. 3.071, de 1. de janeiro de 1916: Código Civil Brasileiro. In: Código Civil. 19. a ed. São Paulo: Saraiva, 2004.

. Lei 22 de setembro de 1822, de 22 de setembro de 1828. Disponível em: http://www.planalto.gov.br/ccivil_03/leis/lim/LIM-18-9-1828 Acesso em 18/08/2021.

Lei 3.133/57, de 8 de maio de 1957. Disponível em: http://www.planalto.gov.br/ccivil.03/leis/1950-1969/13133 Acesso: 18/08/2021.

Lei 4.655/65, de 2 de junho de 1965. Disponível em: http://www2.camara.leg.br/legin/fed/lei/1960-1969/lei-4655-2-junho-1965-377680publicacaooriginal-45829-pl Acesso em: 18/08/2021.

. Lei 6.697/79, de 10 de outubro de 1979. Disponível em: https://www2.camara.leg.br/legin/fed/lei/1970-1979/lei-6697-10-outubro-1979365840-publicacaooriginal-1-pl Acesso: 18/08/2021.

Estatuto da Criança e do Adolescente, de 13 de julho de 1990. Disponível em: http://www.planalto.gov.br/ccivil_03/leis/18069 Acesso em: 18/08/2021.

Decreto n.o 99.710/90, de 21 de novembro de 1990. Disponível em: http://www.planalto.gov.br/ccivil_03/decreto/1990-1994/d99710 Acesso em: 18/08/2021.

RC: 100872

Link de acesso: https://www.nucleodoconhecimento.com.br/lei/adocao-internacional 
Decreto Lei n.o 3.087/99, de 21 de junho de 1999. Disponível em: http://www.planalto.gov.br/ccivil_03/decreto/d3087 Acesso em: 18/08/2021.

- Lei n.o 10.406/02, de 10 de janeiro de 2002. Disponível em: http://www.planalto.gov.br/ccivil_03/leis/2002/L10406compilada Acesso em: $18 / 08 / 2021$

- Lei n.o 12.010/09, de 3 de agosto de 2009. Disponível em: https://presrepublica.jusbrasil.com.br/legislacao/818490/lei-12010-09 Acesso 18/08/2021.

CASTRO, Luiz Carlos de. Adoção Internacional. 1.ㄹ ed. — Paraná: Viseu, 2019.

DINIZ, Maria Helena. Curso de Direito Civil Brasileiro - Direito de Família. 22. ${ }^{\mathrm{a}}$ ed. São Paulo: Saraiva, 2007, p.483-484 apud CARVALHO, Dimas Messias de Adoção e Guarda, Belo Horizonte: Del Rey, 2010.

DINIZ, Maria Helena. Curso de Direito Civil Brasileiro: Direito de Família. 38. ed. São Paulo: Saraiva, 2021.

HAIA. Convenção Relativa à Proteção das Crianças e à Cooperação em Matéria de Adoção Internacional. De 29 de maio de 1993. Disponível em: http://www.planalto.gov.br/ccivil_03/decreto/d3087.htm Acesso: 14/04/2021

LIBERATI, Wilson Donizeti. Manual de Adoção Internacional. 1. ㄹ ed. - São Paulo: Malheiros Editores, 2009.

NUCCl, Guilherme de Souza. Estatuto da Criança e do Adolescente Comentado. 5. ㄹ ed. São Paulo: Editora Forense, 2021.

ONU, Declaração Universal dos Direitos da Criança. De 20 de novembro de 1959. Disponível em: https://crianca.mppr.mp.br/pagina-1069 Acesso em: 18/08/2021. 
ONU, Convenção sobre os Direitos da Criança, De 20 de novembro de 1989. Disponível em: https://www.unicef.org/brazil/convencao-sobre-os-direitos-da-crianca Acesso em: 18/08/2021.

VADE MECUM. Acadêmico de Direito Ridael/Anne Joyce Angher, organização. 30.. ed. - São Paulo: Ridael, 2020.

VENOSA, Sílvio de Salvo. Direito Civil: Direito de Família. 18. ${ }^{a}$ edição. São Paulo: Atlas, 2018.

Enviado: Outubro, 2021.

Aprovado: Novembro, 2021. 